\title{
Influence of High Power Nd: YAG Laser on Hardness and Surface Properties of Zirconium Silicate
}

\author{
Alaa Salahaldin Awadala ${ }^{1}$, Ahmed Elhassan Elfaky ${ }^{1}$, and Ali A. S. Marouf ${ }^{2 *}$ \\ ${ }^{1}$ Department of Physics, College of Science, Sudan University of Science and Technology, Khartoum, Sudan; \\ ${ }^{2}$ Department of Laser Engineering and Industrial Applications, Institute of Laser, Sudan University of Science and \\ Technology, Khartoum, Sudan. \\ *Correspondence: marouf.44@gmail.com (Ali A. S. Marouf, Associate Professor, Department of Laser Engineering and \\ Industrial Applications, Sudan University of Science and Technology, Sudan).
}

\begin{abstract}
Different parameters like irradiated area, irradiation time, laser wavelength, pulse energy, and the nature of the irradiated material determine largely the effect of the laser-matter interaction. In this, study the influence of high power Nd: YAG laser irradiation on the hardness and surface properties of zirconium silicate $\left(\mathrm{ZrSiO}_{4}\right)$ ceramics was investigated. Specimens of zirconium ceramic pieces were divided into four samples depend on irradiation duration as follows: one reference sample and three samples treated with $\mathrm{Nd}$ : YAG laser at irradiation times vary from 3 to 5 minutes. The irradiation was done with $60 \mathrm{~W}$ output power. The hardness and tensile strength were determined and the optical properties were characterized by UV-vis spectroscopy, also EDX spectra were carried out. The obtained results revealed that high power $(60 \mathrm{~W}) \mathrm{Nd}$ : YAG laser provides higher hardness compared to the reference sample surface. Increasing irradiation time resulted in the higher hardness of the ceramic surfaces. EDX results showed that laser irradiation does not change the chemical surface composition of ceramics. Moreover, increase in transmittance of the irradiated zirconium silicate in the visible and near-infrared range was also found using UV-vis spectroscopy.
\end{abstract}

Keywords: Hardness, Laser irradiation, Laser-matter interaction, Surface solidification, Zirconium silicate.

\section{INTRODUCTION:}

Lasers have diverse applications in different fields such as industrial, medical, research, military and some other different fields. In industrial field laser can used in many processes such as welding, cutting, drilling or surface solidifications. Laser-matter effects can be in diversified manners such as photothermal represented by vaporization, ablation of matter based on absorption or in photochemical direct breakage of chemical matter bonds. Zirconia ceramic is a functional material and it has a senior position between ceramic materials. Its special properties, such as high mechanical strength, flexural resistance, make this ceramic material ideal for esthetic crowns, bridges, and frameworks in the anterior and posterior region (El-Ghany and Sherief,
2016). There have been numerous research studies the effect of laser matter irradiation; for example, laser milk pasteurization (Marouf and Sara, 2018; Amna and Marouf, 2018), solar cell surface modification (Marouf et al., 2014, Islam et al., 2020), bee honey irradiation (Al Humira and Marouf, 2017) and production of highly value materials from agricultural waste (Gawbah et al., 2017; Gawbah et al., 2018). There have been numerous research studies the interaction of lowlevel lasers with biological materials such as blood; for examples; studding of $\mathrm{He}-\mathrm{Ne}$ laser effect on human whole blood (Haimid et al., 2019a), investigating the effect of $\mathrm{He}-\mathrm{Ne}$ laser on human whole blood (Haimid et al., 2019b), and it also used to induce emission in human teeth to distinguish 
between dental caries and sound teeth (Marouf and Khairallah, 2019).

Meanwhile, ceramic materials in structural applications burned by large kilns to enhance its mechanical and surface properties. Also, different ceramic compositions are available for dental use, with varying properties that respond to different clinical indications. Now a days, the Nd: YAG laser has been suggested for employing to dental hard tissues for various usages, such as the impact of laser irradiation on dental restorative materials surface morphology (Sanusi et al., 2012; Garcia-Sanz et al., 2018), surface modification of Ti dental implants by laser (Braga et al., 2014), laser treatment of dental ceramic/cement layers (Pich et al., 2015), effects of laser on filling materials (Türkmen et al., 2006) and effect of laser in hardness of dental ceramic (Ahmed et al., 2014). The main objective of this study is correlating the high power Nd: YAG laser irradiation duration time with the hardness of the zirconium silicate irradiated surface.

\section{MATERIALS AND METHODS:}

Specimens - The materials used were commercial which went through the following stage: first grinding raw materials (Nile clay, silica sand, weather granite, kaolin, sodium silica, S.T.P.P, master mix) and then sprayed and kept in silos and pressed using (SAMI PH3590 PRESS) and pressed from 160 to $180 \mathrm{Bar}$, and then dried and it passed the glaze line which consists of (quartz, feldspar, Ball clay, I. Kaolin, Engobe frit-19, matt frit-13, opaque frit-188, Transparent frit-575, Zirconium silicate $\left(\mathrm{ZrSiO}_{4}\right)$, calcined alumina, transparent printing-106, transparent printing-1000, reactive printing powder606 ), four rectangular specimens A, B, C and D were made with length of $2 \mathrm{~cm}$, width $1 \mathrm{~cm}$ and thickness $2 \mathrm{~mm}$. Three of these specimens (B, C and D) were exposed Nd: YAG laser with $60 \mathrm{~W}$ output power at continuous mode, with different irradiation times (3, 4, and 5) min and one specimen was left without treatment (A) as reference.

Laser Irradiation - An Nd: YAG laser system (Dornier Medilas fiber to 5100) operating at a wavelength of $1064 \mathrm{~nm}$ with continuous mode was used to irradiate specimen. Specimens were placed one by one and the $\mathrm{Nd}$ : YAG laser beam was projected perpendicular to the surface of the specimens. The distance from the laser window to the specimen surface was approximately $7 \mathrm{~mm}$. The laser power was $60 \mathrm{~W}$ and laser irradiation treatments were carried out without any water spray (dry laser). All tests and characterizations were done on the exposed area in the samples.

Hardness and Tensile Strength Tests-The hardness of the irradiated and non-irradiated sites were tested using the Vickers Hardness method (ZHU250, ZWICK/ROELL, GERMANY, 2015). The Vickers indenter is a 136 degrees square-based diamond pyramid. This method is more accurate than Brinell method; because of its impression is clearer than the impression of Brinell indenter. The applied load, was in the range of $1 \mathrm{kgf}$ to $120 \mathrm{kgf}$, for 30 seconds. The following formula is used to calculate the Vickers number (HV):

$$
\mathrm{HV}=1.854 \times \mathrm{F} / \mathrm{D}^{2}
$$

Where, $\mathrm{D} \equiv$ length of the impression diagonal/ $\mathrm{mm}$; $\mathrm{F} \equiv$ applied load $/ \mathrm{kg}$.

Microscope used to measure the length of the impression diagonal, which is always an integral part of the Vickers Tester. Tensile strength was determined utilizing the equation below:

$$
\mathrm{Ts}=3.45 \times \mathrm{HB}
$$

EDX Analysis - An analysis of the chemical composition (EDX) of the surface layer was made for the irradiated specimens. More quantitative elemental information were collected from the sample by the characteristic X-rays (EDX analysis) using (Libusinatrida 863/21, Brno, Czech Republic)with a local analysis of the chemical composition.

UV-vis spectroscopy - To identify the effect of laser irradiation on the absorbance of the irradiated specimens and the non-irradiated specimens an aqueous suspension of the zirconium silicate was carried out using a Jasco-670 UV-Visible spectrometer.

\section{RESULTS AND DISCUSSION:}

The photothermal effect of the irradiation of zirconium silicate specimens using Nd: YAG laser at $1064 \mathrm{~nm}$ wavelength and $60 \mathrm{~W}$ output power with continuous mode for different durations generates heat which caused in the following results: 
Hardness and Tensile Strength Results - The results of irradiation utilizing Nd: YAG laser (power $60 \mathrm{~W})$ at different duration time $(0,3,4$ and 5) minutes on the zirconium silicate specimens' hardness were listed in Table 1. It shows that the hardness of the irradiated samples was obviously increased. A considerable increasing in hardness with increasing irradiation time from 3 to 5 minutes was found; it changed at a constant irradiation time at one minute. It increased about one third (37.5\%) at irradiation time three minutes, it increased the half $(50 \%)$ at four minutes and about two thirds $(62.5 \%)$ at five minutes.

The results of irradiation on the zirconium silicate specimens' tensile strength were listed in Table 2. It was calculated by applying the following equation:

$$
\mathrm{Ts}=3.45 \times \mathrm{HB}
$$

The experimental data presented in Tables $\mathbf{1}$, and $\mathbf{2}$ show that, in all experiments, a linear correlation between hardness or tensile strength and laser irradiation time was detected. Fig 2 depict (A) depict the linear correlation between tensile strength and irradiation time, While Fig 2(B) depict the linear correlation between tensile strength change and irradiation time. Fig 1(A) depict the linear correlation between hardness and irradiation time. While Fig 1 (B) depict the linear correlation between hardness change and irradiation time. Graphs in Fig 1, and 2 presented that increasing irradiation time resulted in higher hardness of the ceramic surfaces.

Table 1: Hardness results for untreated zirconium silicate sample (A) and zirconia treated with Nd: YAG laser specimens (B, C and D).

\begin{tabular}{|c|l|l|l|l|}
\hline Sample & \multicolumn{1}{|c|}{$\begin{array}{c}\text { Hardness/ } \\
\mathbf{H V = 1 . 8 5 4 4} \text { F/D }\end{array}$} & Hardness/HB & \multicolumn{1}{|c|}{$\begin{array}{c}\text { Hardness } \\
\text { changes/HB }\end{array}$} & \multicolumn{1}{|c|}{ Change \% } \\
\hline A & 8.1 & 8 & 0 & 0 \\
\hline B & 10.5 & 11 & 3 & 37.5 \\
\hline C & 11.7 & 12 & 4 & 50 \\
\hline D & 12.6 & 13 & 5 & 62.5 \\
\hline
\end{tabular}

Table 2: Tensile strength results for untreated zirconium silicate sample (A) and zirconia treated with Nd: YAG laser specimens (B, C and D).

\begin{tabular}{|c|l|l|l|l|}
\hline Sample & Hardness/ HB & \multicolumn{1}{|c|}{$\begin{array}{c}\text { Tensile strength/ } \\
\text { MPa }\end{array}$} & $\begin{array}{c}\text { Tensile strength } \\
\text { changes/ MPa }\end{array}$ & Change \% \\
\hline A & 8 & 27.6 & 0 & 0 \\
\hline B & 11 & 37.95 & 10.35 & 27.27 \\
\hline C & 12 & 41.4 & 13.8 & 33.33 \\
\hline D & 13 & 44.85 & 17.25 & 38.46 \\
\hline
\end{tabular}
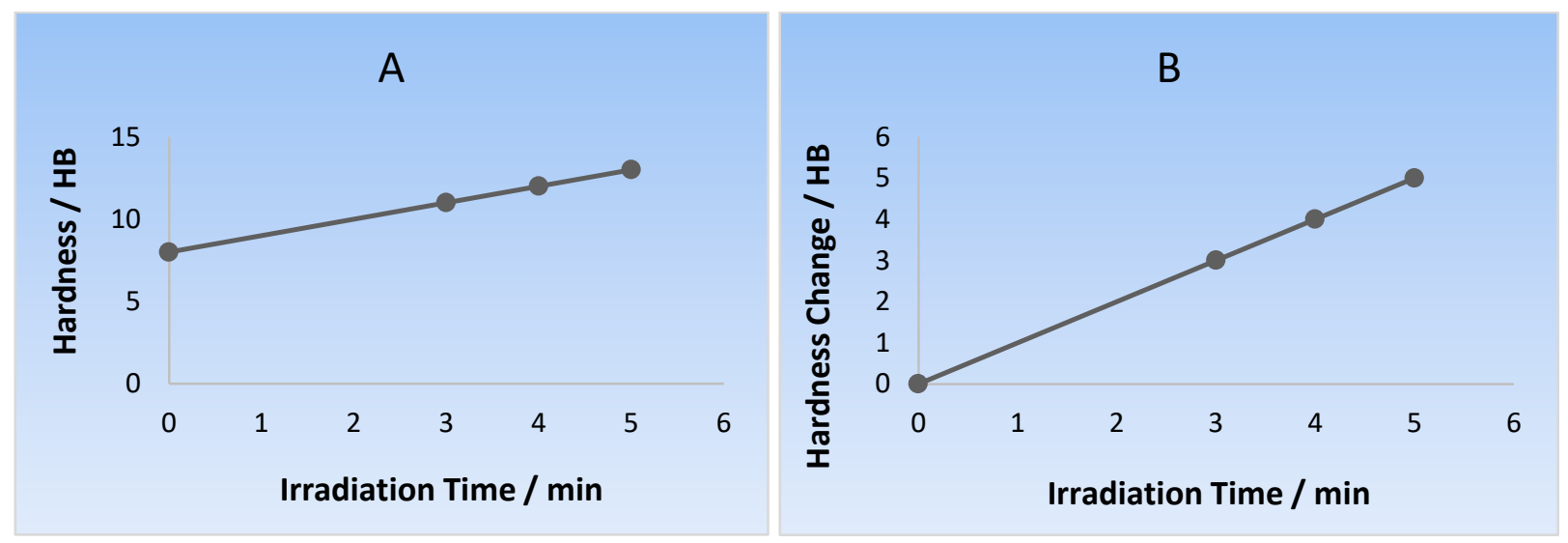

Fig 1: Effect of irradiation time on zirconium silicate samples' - (A) hardness, (B) change in hardness. 

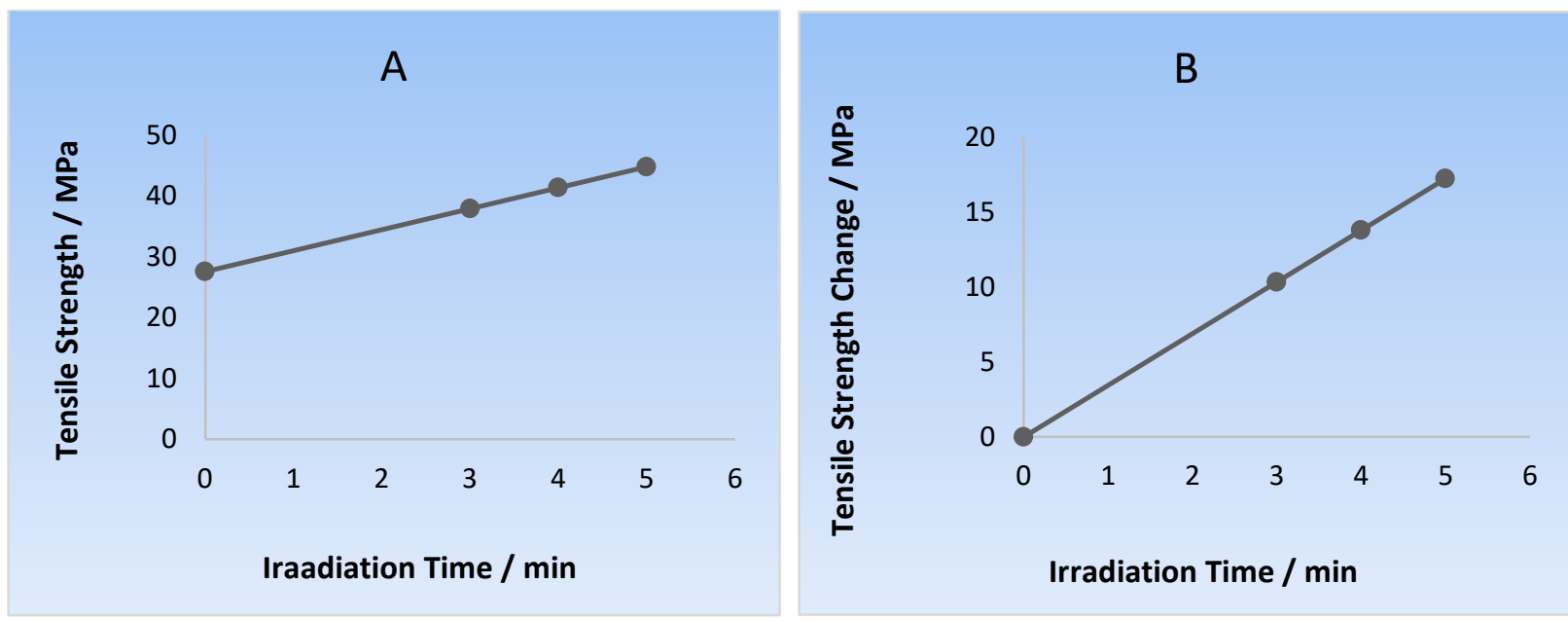

Fig 2: Effect of irradiation time on zirconium silicate samples' - (A) tensile strength, (B) tensile strength change.

EDX Results - The EDX spectra shown in Fig 3 giving the elemental analysis data of the samples before and after laser irradiation treatment with 4 minutes and 5 minutes. The presence of the same elements is coincides with the results from laser irradiated and non-irradiated specimens, which mean that laser irradiation do not change the chemical surface composition of ceramics. EDX spectra show that the zirconium and silicon have the highest peaks compared to the other elements as shown in Table 3.

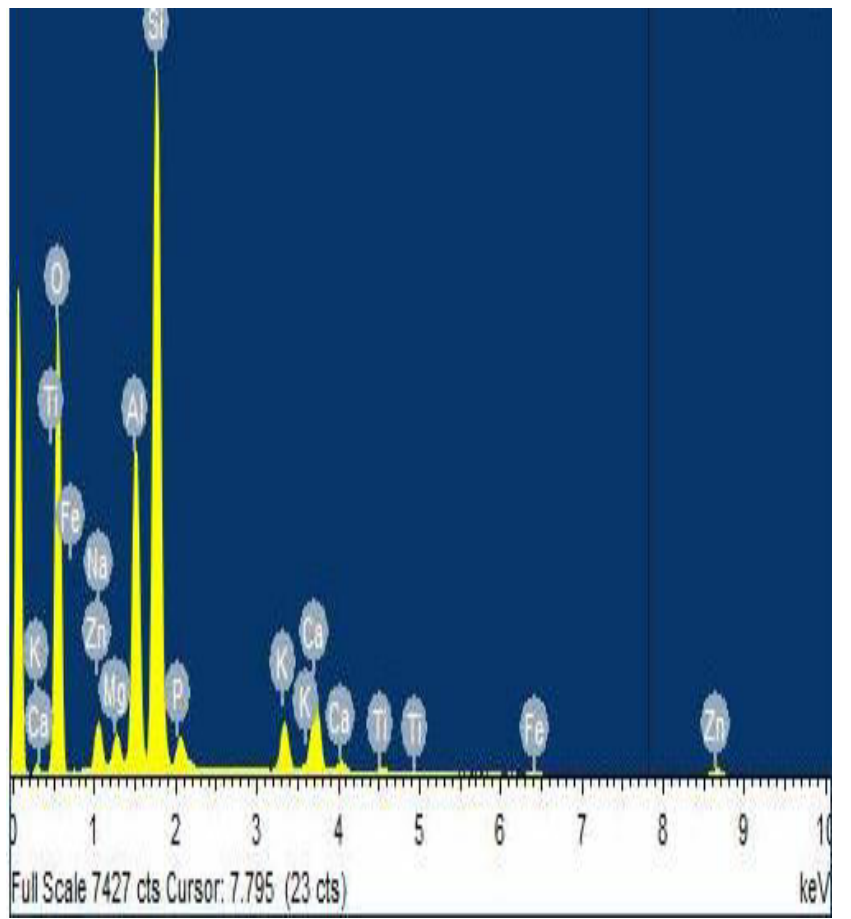

(A)

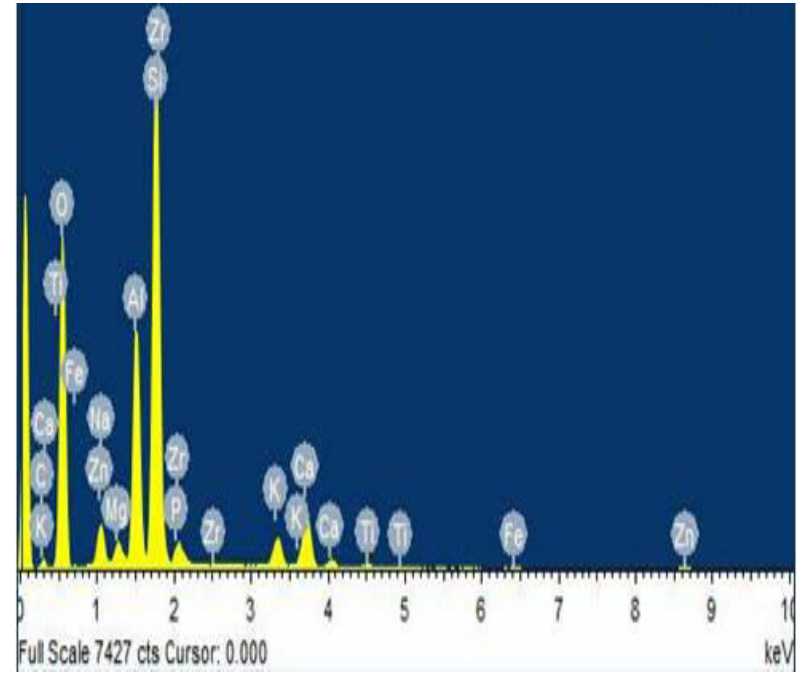

(B)

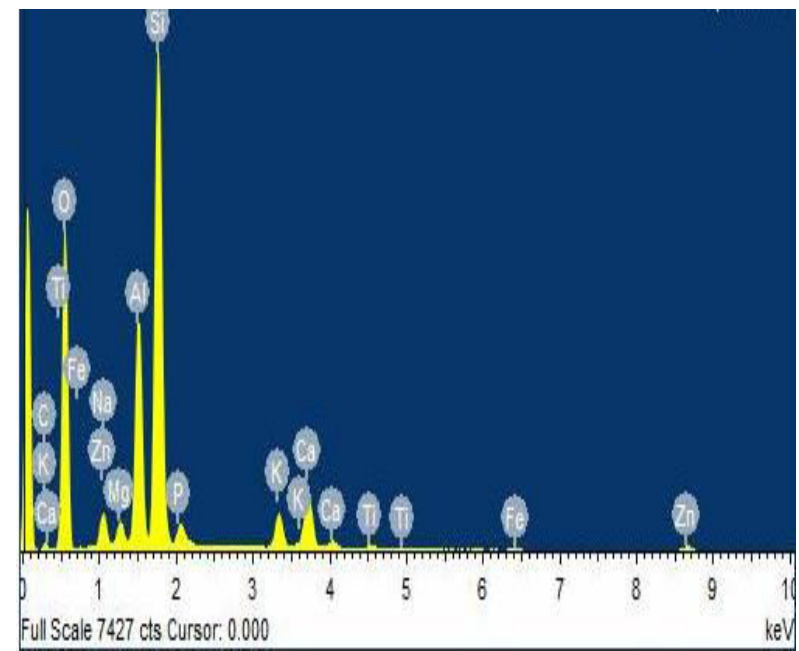

(C)

Fig 3: EDX spectra of zirconium silicate - (A) before, (B); and (C) after Nd: YAG laser irradiation (60 W): 0,4 , and 5 min irradiation duration respectively. 
Table 3: EDX results of zirconium silicate sample; (A) before, sample (B), and samples (C) after Nd: YAG laser irradiation $(60 \mathrm{~W})$ : 0,4 and 5 min irradiation duration respectively.

\begin{tabular}{|c|c|c|c|c|c|c|}
\hline \multirow{2}{*}{ Element } & \multicolumn{2}{|c|}{ Sample A } & \multicolumn{2}{c|}{ Sample C } & \multicolumn{2}{c|}{ Sample D } \\
\cline { 2 - 7 } & Weight\% & Atomic\% & Weight\% & Atomic\% & Weight\% & Atomic\% \\
\hline $\mathrm{C} \mathrm{K}$ & 0 & 0 & 2.95 & 4.87 & 6.20 & 10.04 \\
\hline $\mathrm{O} \mathrm{K}$ & 54.14 & 68.64 & 54.31 & 67.30 & 51.70 & 62.82 \\
\hline $\mathrm{Na} \mathrm{K}$ & 1.70 & 1.50 & 1.61 & 1.39 & 1.88 & 1.59 \\
\hline $\mathrm{Mg} \mathrm{K}$ & 1.09 & 0.91 & 0.89 & 0.73 & 0.81 & 0.65 \\
\hline $\mathrm{Al} \mathrm{K}$ & 9.51 & 7.15 & 8.94 & 6.57 & 8.78 & 6.32 \\
\hline $\mathrm{Si} \mathrm{K}$ & 23.59 & 17.03 & 21.25 & 15.00 & 21.19 & 14.67 \\
\hline $\mathrm{P} \mathrm{K}$ & 1.24 & 0.81 & 0.64 & 0.41 & 1.21 & 0.76 \\
\hline $\mathrm{K} \mathrm{K}$ & 2.22 & 1.15 & 1.76 & 0.89 & 1.75 & 0.87 \\
\hline $\mathrm{Ca} \mathrm{K}$ & 3.71 & 1.88 & 3.45 & 1.71 & 3.23 & 1.57 \\
\hline $\mathrm{Ti} \mathrm{K}$ & 0.26 & 0.11 & 0.23 & 0.09 & 0 & 0 \\
\hline Fe K & 0.57 & 0.21 & 0.29 & 0.10 & 0.27 & 0.09 \\
\hline Zn K & 1.97 & 0.61 & 1.73 & 0.52 & 1.63 & 0.49 \\
\hline Zr L & 0 & 0 & 1.96 & 0.43 & 0 & 0 \\
\hline Pt M & 0 & 0 & 0 & 0 & 1.34 & 0.13 \\
\hline Totals & $\mathbf{1 0 0 . 0 0}$ & & $\mathbf{1 0 0 . 0 0}$ & & $\mathbf{1 0 0 . 0 0}$ & \\
\hline
\end{tabular}

UV-vis spectroscopy Results - The UV-vis spectroscopy spectra of the four samples are shown in Fig 4. Decreased absorbance was observed in the laserirradiated samples in the visible and near infrared range $(350-800 \mathrm{~nm})$. When comparing non-irradiated sample with each of the laser irradiated samples, non-irradiated sample always showed higher absorbance. The process of laser irradiation presented effect in transmittance of the zirconium silicate.

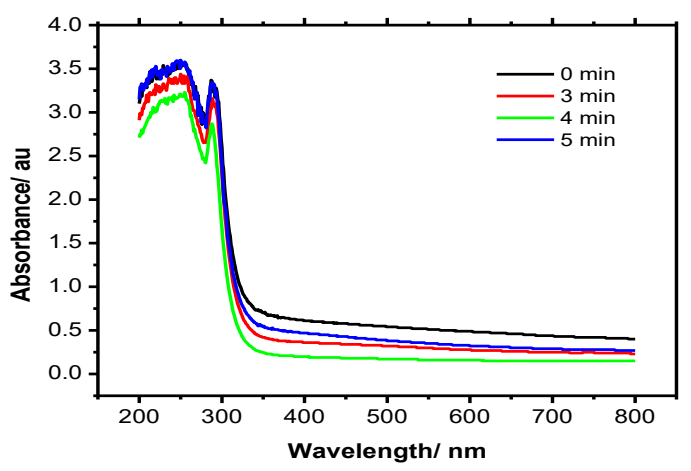

Fig 4: UV spectra of zirconium silicate specimens before and after laser irradiation.

\section{CONCLUSION:}

In summary, the experimental results obtained from high power Nd: YAG laser irradiation of zirconium silicateshow that the hardness of zirconium silicate could be increased with irradiation. A linear UniversePG I www.universepg.com correlation between hardness or tensile strength and laser irradiation time was detected. EDX results reveal that laser irradiation do not change the chemical surface composition of ceramics. Moreover, UV-vis spectra show more transmittance of irradiated zirconium silicate specimens compared to the non-irradiated specimens. Nd: YAG laser irradiation with $(60 \mathrm{~W})$ can increase the hardness of zirconium silicate ceramics.

\section{ACKNOWLEDGEMENT:}

First, we would like to express our heart full appreciation to almighty God. Secondly, to institute of laser in accessing the instrumentation and lastly to in institute of laser and college of science, Sudan University of Science and Technology.

\section{CONFLICT OF INTERESTS:}

There is no conflict of interest between the authors.

\section{REFERENCES:}

1. Ahmed, M.M., Abdelrahman, A.H., Mohieldin, E. and Yagoub, S.O. (2014). Effect of Diode Laser 810nm in Hardness of Dental Ceramic. Optics and Photonics Journal, 4, 104-112. http://dx.doi.org/10.4236/opj.2014.45011

2. Al Humira Elseir Gorashe Ahmmed, A. and Marouf, A.S. (2017). Effect of Pulsed He-Ne 
Laser Irradiation on Bee Honey Physicochemical Properties. The Saudi Journal of Life Sciences (SJLS), 2(9), 378-387. http://dx.doi.org/10.21276/haya.2017.2.9.11

3. Amna O.B Malik and Marouf, A.A. (2018). Comparison of the Effects of Laser Pasteurization and Heat Pasteurization on The Cow's Milk, Haya: The Saudi Journal of Life Sciences, 3(1), 46-50. http://dx.doi.org/10.21276/haya.2018.3.1.9

4. Braga, F.J., Marques, R.F. and Guastaldi, A.C. (2014). Surface modification of $\mathrm{Ti}$ dental implants by $\mathrm{Nd}: \mathrm{YVO}_{4}$ laser irradiation. Applied Surf. Sci., 253(23), 9203-9208. http://dx.doi.org/10.1016/j.apsusc.2007.05.048

5. El-Ghany, O.S.A. and Sherief, A.H. (2016). Zirconia based ceramics, some clinical and biological aspects. Future dental journal, 2(2), pp.55-64. http://dx.doi.org/10.1016/j.fdj.2016.10.002

6. Garcia-Sanz, V., Paredes-Gallardo, V., Mendoza Yero, and Bellot-Arcis, C. (2018). The effects of lasers on bond strength to ceramic materials: A systematic review and meta analysis. PloS one, 13(1), e0190736. https://doi.org/10.1371/journal.pone.0190736

7. Gawbah, M.A.P., Elbadawi, A.A., and Marouf, A.A. (2018). Characterization of the Crystal Structure of Sesame Seed Cake Burned by Nd: YAG Laser. J. of Materials Science and Chemical Engi., 6(4), p.121. https://doi.org/10.4236/msce.2018.64013

8. Gawbah, M.A.P., Marouf, A.A., and Elbadawi, A.A. (2017). Synthesis of Silica, Silicon Carbide and Carbon from Wheat Bran and Converting Its Crystal Structure Using Nd: YAG Laser. future, 2, p.9.

9. Haimid, M.A., Marouf, A.A. and Abdalla, M.D. (2019a). Helium-Neon Laser Effects on Human Whole Blood by Spectroscopy In vitro Study. Asian J. of Physical and Chemical Sciences, 7(1), pp. 2456-7779. https://doi.org/10.9734/AJOPACS/2019/46214
10. Haimid, M.A., Marouf, A.A. and Abdalla, M.D. (2019b). In vitro UV-Visible and FTIR Spectroscopy Study of Low Power He-Ne Laser Irradiation on Human Blood. Asian J. of Research and Reviews in Physics, pp.1-7. https://doi.org/10.9734/AJR2P/2019/46527

11. Islam T., Akter N. and Jahan N. (2020). MHD free convective heat transfer in a triangular enclosure filled with Copperwater nanofluid, Int. J. Mat. Math. Sci., 2(2), 29-38.

https://doi.org/10.34104/ijmms.020.029038

12. Marouf, A. and Sara, I.E. (2018). Monitoring $\mathrm{pH}$ During Pasteurization of Raw Cow's Milk using Nd: YAG Laser. International Journal of Advanced Research in Physical Science, 4(12), 1-4.

13. Marouf, A.A., Abdalah, S.F., Abdul-rahman, W.S. and Al Naimee, K. (2014). The Role of photonic Processed Si Surface in Architecture Engineering. Study of Civil Engineering and Architecture, 3, pp.93-97.

14. Marouf, A.A., Khairallah Y. A. (2019). Photoemission Spectra of Sound Tooth and Those of Different Carious Stages. European J. of Biophysics. 7(1), pp. 23-26. https://doi.org/10.11648/j.ejb.20190701.14

15. Pich, O., Franzen, R., Gutknecht, N. and Wolfart, S. (2015). Laser treatment of dental ceramic layers: transmitted energy, temperature effects and surface character-ization. Lasers in medical science, 30(2), 591-597. https://doi.org/10.1007/s10103-013-1340-3

16. Sanusi, S., Seow, W.K. and Walsh, L.J. (2012). Effects of Er: YAG laser on surface morphology of dental restorative materials. J. of Physical Science, 23(2), pp.55-71.

17. Türkmen, C., Sazak, H. and Günday, M. (2006). Effects of the Nd: YAG laser, airabrasion and acid-etchant on filling materials. J. of oral rehabilitation, 33(1), 6469. 